\title{
Analisis Faktor Yang Mempengaruhi Financial Saticfaction Pada Dosen Di Universitas Papua
}

\author{
Agustia Said $^{1}$, Nurwidianto ${ }^{2}$, Selmi Dedi ${ }^{3}$ \\ ${ }^{1}$ Alumni Jurusan Manajemen, Universitas Papua \\ ${ }^{2,3}$ Dosen Jurusan Manajemen, Universitas Papua
}

\begin{abstract}
Abstrak
Penelitian ini bertujuan untuk mengetahui apakah financial knowledge, financial capability dan financial behavior secara parsial dan secara simultan berpengaruh terhadap financial saticfaction. Kemudian untuk mengetahui faktor manakah yang paling dominan berpengaruh terhadap financial saticfaction.

Jenis penelitian ini adalah kuantitatif. Menggunakan data yang bersifat angka-angka dianalisis. Sampel dalam penelitian ini menggunakan proportionate stratified random sampling. Tehnik pengumpuan data menggunakan kuisioner yang disebar kepada dosen di Universitas Papua sebanyak 83 sampel. Data dianalisis menggunakan uji validitas dan reliabilitas, uji asumsi klasik, analisis regresi berganda (uji koefisien determinasi, uji t dan uji F) dengan bantuan software SPSS 21. Hasil penelitian menunjukkan bahwa variabel financial knowledge dan financial behavior berpengaruh secara parsial terhadap financial saticfaction. Sedangkan financial capability tidak berpengaruh secara parsial terhadap financial saticfaction. Secara simultan financial knowledge, financial capability dan financial behavior berpengaruh terhadap financial saticfaction. Kemudian variabel financial behavior paling dominan berpengaruh terhadap financial saticfaction.
\end{abstract}

Kata kunci: Financial Knowledge, Financial Capability, Financial Behavior, Financial Saticfaction

\begin{abstract}
The purpose of this study is to know whether financial knowledge, financial capability and financial behavior in partially and simultaneously that have affect to financial saticfaction. Then, to know which is most dominant factor that effect to financial saticfaction. The type of this research is quantitative that using numerical data to analyzed. The sample in this research is using proportionate stratified random sampling. Which is technique of collecting the data that using questionare distributed to lecturer at Universitas of Papua counted 83 samples. The data were analyzed using validity and reliability test, classic assumption test, multiple regression analysis (determination coefficient test, F tes and T Test) with SPSS 21 software support. The results of this study showed that the variables of financial knowledge and financial behavior influenced partially to financial saticfaction. While financial capability does not effect partially to financial saticfaction. Simultaneously, financial knowledge, financial capability and financial behavior have an effect to financial saticfaction. Then, the most dominant variable of financial behavior is affect to financial saticfaction.
\end{abstract}

Keywords: Financial Knowledge, Financial Capability, Financial Behavior, Financial Saticfaction

How to Cite: Said, A., Nurwidianto, Dedi, S., (2020). Analisis Faktor Yang Mempengaruhi Financial Saticfaction Pada Dosen Di Universitas Papua. JFRES: Journal of Fiscal and Regional Economy Studies, 2 (2), $47-51$.

\footnotetext{
Corresponding author:

E-mail: n.nurwidianto@unipa.ac.id
} 


\section{PENDAHULUAN}

Pada era modern saat ini dimana berkembangnya Ilmu Pengetahuan dan Teknologi disertai meningkatnya perilaku konsumtif masyarakat secara menyeluruh baik yang dewasa maupun remaja. Perilaku konsumtif adalah perilaku timbulnya keinginan untuk membeli suatu barang yang sebenarnya bukan menjadi kebutuhannya. Hal tersebut diperparah dengan semakin banyaknya toko online yang tersedia saat ini sehingga mempermudah masyarakat dalam aktifitas berbelanja.

Otoritas Jasa Keuangan (OJK) pada tahun 2015 menyatakan bahwa masyarakat Indonesia semakin konsumtif dan mulai meninggalkan kebiasaan menabung. Hal itu tergambar dari data menurunnya Marginal Propensity to Save (MPS) dan naiknya Marginal Propensity to Consume (MPC) selama 3 tahun terakhir sebelum tahun 2015 (kompas.com, 2017).

Berdasarkan data dari Bank Indonesia (BI), Kabupaten Manokwari merupakan salah satu daerah dimana masyarakatnya memiliki tingkat konsumtif yang semakin meningkat setiap tahunnya. Hal tersebut dapat dilihat pada tabel 1 untuk kredit konsumtif masyarakat di Kabupaten Manokwari dari tahun 2012 sampai tahun 2016.

Tabel 1. Jumlah Kredit Konsumtif Masyarakat Kabupaten Manokwari

\begin{tabular}{ccc}
\hline No & Tahun & Jumlah Kredit \\
\hline 1 & 2012 & Rp. $6.407 .554 .205 .927,-$ \\
\hline 2 & 2013 & Rp. $8.244 .500 .781 .473,-$ \\
\hline 3 & 2014 & Rp. $9.460 .599 .980 .855,-$ \\
\hline 4 & 2015 & Rp.11.716.467.473.853,-- \\
\hline 5 & 2016 & Rp.12.468.198.505.764,-- \\
\hline
\end{tabular}

Sumber: Bank Indonesia, 2017

Kegiatan ekonomi adalah kegiatan seseorang atau sekumpulan orang (perusahaan) untuk memproduksi barang dan/atau jasa maupun mengkonsumsi (menggunakan) barang dan/atau jasa tersebut. Umumnya kegiatan ekonomi terdiri dari kegiatan konsumsi, produksi dan distribusi. Barang dan jasa yang dihasilkan dari kegiatan produksi, nantinya akan didistribusikan untuk bisa menjangkau konsumen, agar konsumen dapat memenuhi kebutuhannya.

Tabel 1 menunjukkan terjadinya peningkatan kredit konsumtif masyarakat di Kabupaten Manokwari yang cukup tinggi. menunjukkan bahwa masyarakat di Kabupaten Manokwari kebanyakan menggunakan kredit untuk memenuhi kebutuhan konsumsi, tanpa memperhitungkan resiko yang akan ditanggung. Perilaku keuangan yang konsumtif ini tentu akan mempengaruhi kepuasan masyarakat dalam memperoleh manfaat yang diterima. Menurut Joo dan Grable (2004), Kepuasan keuangan (financial saticfaction) dipengaruhi oleh berbagai faktor, bukan saja faktor perilaku keuangan, faktor-faktor lain yang dapat mempengaruhi kepuasan keuangan yaitu pengetahuan keuangan, dan pendapatan.

Financial knowledge sangat berkaitan erat dengan financial literacy dimana berdasarkan riset terbaru di tahun 2016 yang dilakukan oleh Otoritas Jasa Keuangan (OJK) yaitu masyarakat Indonesia memiliki literasi keuangan sebesar 29,6\% sementara di tahun 2013 sebesar 21,8\%. Meskipun terjadi peningkatan literasi keuangan, ini artinya bahwa sebagian besar masyarakat Indonesia masih memiliki pengetahuan yang cukup rendah dalam hal literasi keuangan bahkan masyarakat yang memiliki jenjang pendidikan yang lebih tinggi.

Variabel lainnya yang dapat mempengaruhi perilaku keuangan juga dapat ditentukan oleh jumlah pendapatan hal tersebut dapat dibuktikan dari hasil penelitian yang dilakukan oleh Andrew dan Linawati (2014) menunjukkan bahwa tingkat pendapatan mempunyai hubungan signifikan terhadap perilaku keuangan karyawan swasta di Surabaya. Pada perkembangannya saat ini pengetahuan mengenai keuangan mulai diperkenalkan diberbagai jenjang pendidikan dan berbagai usia baik kalangan muda maupun tua, termasuk perguruan tinggi dan salah satu Perguruan Tinggi yang terdapat di Indonesia adalah Universitas Papua (Unipa).

Universitas Papua (Unipa) merupakan salah satu perguruan tinggi di Provinsi Papua Barat, yang pendiriannya ditetapkan dengan Keputusan Presiden Republik Indonesia No. 153 Tahun 2000. Pada tahun 2005 UNIPA menyelenggarakan proses pembelajaran pada 21 Program Studi S1 dan 10 Program Studi S0 yang tersebar di 6 Fakultas (Peraturan Akademik Unipa, 2009). Pada Tahun 2017 Unipa menunjukkan pertumbuhan dengan bertambahnya jumlah Fakultas dan Program Studi dimana sampai saat ini mempunyai 13 Fakultas dan 46 Program Studi (Peraturan Akademik Unipa, 2009). Berikut adalah data jumlah fakultas dan jumlah dosen yang berstatus aktif mengajar di Universitas Papua. 
Tabel 2. Jumlah Dosen Aktif Mengajar Berdasarkan Fakultas di Universitas Papua

\begin{tabular}{|c|c|c|c|c|c|c|c|c|}
\hline \multirow[t]{2}{*}{ No } & \multirow{2}{*}{ Nama Fakultas } & \multicolumn{2}{|c|}{$\begin{array}{c}\text { Jenis } \\
\text { Kelamin }\end{array}$} & \multicolumn{4}{|c|}{ Pendidikan } & \multirow{2}{*}{$\begin{array}{c}\text { Total } \\
\text { (Orang) }\end{array}$} \\
\hline & & $\mathbf{L}$ & $\mathbf{P}$ & Prof & S3 & S2 & S1 & \\
\hline 1 & FEB (Fakultas Ekonomi dan Bisnis) & 27 & 24 & - & 4 & 40 & 7 & 51 \\
\hline 2 & FAPERTA (Fakultas Pertanian) & 46 & 47 & 1 & 19 & 71 & 2 & 93 \\
\hline 3 & $\begin{array}{l}\text { FATETA (Fakultas Teknologi } \\
\text { Pertanian) }\end{array}$ & 15 & 17 & - & 8 & 23 & 1 & 32 \\
\hline 4 & F.SASTRA (Fakultas Sastra) & 22 & 12 & - & 1 & 28 & 5 & 34 \\
\hline 5 & $\begin{array}{l}\text { FMIPA (Fakultas Matematika Ilmu } \\
\text { dan Pengetahuan Alam) }\end{array}$ & 18 & 31 & - & 9 & 39 & 1 & 49 \\
\hline 6 & F.HUTAN (Fakultas Kehutanan) & 46 & 25 & 1 & 8 & 51 & 11 & 71 \\
\hline 7 & $\begin{array}{l}\text { FPIK (Fakultas Perikanan dan Ilmu } \\
\text { Kelautan) }\end{array}$ & 27 & 15 & 1 & 6 & 33 & 2 & 42 \\
\hline 8 & $\begin{array}{l}\text { FKIP (Fakultas Keguruan dan Ilmu } \\
\text { Pendidikan) }\end{array}$ & 17 & 18 & - & 2 & 31 & 2 & 35 \\
\hline 9 & FAPERTEK (Fakultas Peternakan) & 27 & 20 & 2 & 11 & 32 & 2 & 47 \\
\hline 10 & F.TEKNIK (Fakultas Teknik) & 15 & 4 & - & 1 & 18 & - & 19 \\
\hline 11 & $\begin{array}{l}\text { FTPP (Fakultas Teknik } \\
\text { Pertambangan dan Perminyakan }\end{array}$ & 13 & 3 & - & - & 16 & - & 16 \\
\hline 12 & Fakultas Kedokteran & 7 & 5 & - & - & 3 & 9 & 12 \\
\hline 13 & Fakultas Pascasarjana & - & - & - & - & - & - & - \\
\hline Tot & Dosen & 280 & 221 & 5 & 69 & 385 & 42 & 501 \\
\hline
\end{tabular}

Sumber: Database UNIPA, 2018

Tabel 2 menunjukkan bahwa total keseluruhan jumlah dosen yang aktif mengajar di Universitas Papua berdasarkan 13 Fakultas yang ada sebanyak 501 orang. Dosen merupakan salah satu tenaga pengajar yang minimal jenjang pendidikannya adalah Sarjana dengan pendapatan yang diperoleh setiap bulan. Berdasarkan latar belakang diatas, maka tujuan penelitian ini adalah ingin mengetahui tentang pengaruh financial knowledge, financial capability dan financial behavior baik secara parsial maupun simultan berpengaruh terhadap financial saticfaction serta faktor manakah yang paling dominan berpengaruh terhadap financial saticfaction pada dosen di Universitas Papua. Penelitian ini juga hanya menggunakan dosen Universitas Papua yang berstatus aktif mengajar dan berada di Manokwari.

\section{METODE PENELITIAN}

\section{Data}

Dari hasil pada tabel 3, apabila ditulis persamaan regresi dalam bentuk unstandardized coefficient sebagai berikut:

$$
\mathrm{Y}=\alpha+\beta 1 \mathrm{X} 1+\beta 2 \mathrm{X} 2+\beta 3 \mathrm{X} 3+\mathrm{e}
$$

\section{Keterangan:}

$\mathrm{Y}=$ Financial saticfaction

$\alpha \quad=$ Konstanta

$\beta \mathrm{i}, \quad=$ Koefisien regresi

$\mathrm{X} 1=$ Financial knowledge

$\mathrm{X} 2$ =Financial capability

$\mathrm{X} 3$ =Financial behavior

$e \quad=$ Error/kesalahan estimasi standar

Tabel 3. Hasil Uji Regresi Linear Berganda Coefficients $^{\mathrm{a}}$

\begin{tabular}{lrrrrr}
\hline \multicolumn{1}{c}{ Model } & \multicolumn{2}{c}{$\begin{array}{c}\text { Unstandardized } \\
\text { Coefficients }\end{array}$} & $\begin{array}{c}\text { Standardized } \\
\text { Coefficients }\end{array}$ & T & Sig. \\
\cline { 2 - 5 } & B & Std. Error & Beta & & \\
\hline (Constant) & 8.460 & 6.510 & & 1.300 & 0.197 \\
\hline Financial Knowledge & 0.411 & 0.201 & 0.197 & 2.040 & 0.045 \\
\hline Financial Capability & -0.015 & 0.173 & -0.009 & -0.088 & 0.930 \\
\hline Financial Behavior & 0.535 & 0.096 & 0.533 & 5.568 & 0.000 \\
\hline
\end{tabular}

a. Dependent Variable: Financial Saticfaction

Sumber: Data primer yang diolah (2018) 
Adapun persamaan regresi diatas dapat dijelaskan sebagai berikut:

1. Konstanta sebesar 8,460 artinya jika financial knowledge (X1), financial capability (X2), dan financial behavior (X3) nilainya adalah 0 , maka financial saticfaction ( $\mathrm{Y}$ ) nilainya adalah 8,460.

2. Koefisien regresi variabel financial knowledge (X1) sebesar 0,411 artinya jika variabel independen lain nilainya tetap dan financial knowledge mengalami kenaikan $1 \%$, maka financial saticfaction akan mengalami peningkatan sebesar 0,411.

3. Koefisien regresi variabel financial capability (X2) sebesar -0,015 artinya jika variabel independen lain nilainya tetap dan financial capability mengalami kenaikan $1 \%$, maka financial saticfaction akan mengalami penurunan sebesar $-0,015$.

4. Koefisien regresi variabel financial behavior (X3) sebesar 0,535 artinya jika variabel independen lain nilainya tetap dan financial behavior (X3) mengalami kenaikan 1\%, maka financial saticfaction akan mengalami peningkatan sebesar 0,535.

Untuk mengetahui apakah masing-masing variabel bebas berpengaruh secara signifikan terhadap variabel terikat maka digunakan Uji T (Ghozali, 2006). Dalam hal ini pengambilan keputusannya dengan menggunakan angka probabilitas signifikansi. Jika $\mathrm{t}$ hitung $\leq \mathrm{t}$ tabel, atau nilai signifikansi $>0,05$ maka $\mathrm{H}_{0}$ diterima dan $\mathrm{H}_{\mathrm{a}}$ ditolak dan jika $\mathrm{t}$ hitung $>\mathrm{t}$ tabel, atau nilai signifikansi $\leq 0,05$ maka $\mathrm{H}_{0}$ ditolak dan $\mathrm{H}_{\mathrm{a}}$ diterima.

Tabel 4. Hasil Uji Parsial (Uji T)

\begin{tabular}{lcc}
\hline \multicolumn{1}{c}{ Variabel } & T & Sig. \\
\hline Financial Knowledge & 2.040 & .045 \\
\hline Financial Capability & -.088 & .930 \\
\hline Financial Behavior & 5.568 & .000 \\
\hline
\end{tabular}

Sumber: Data primer yang diolah (2018)

Pada tabel 4 diperoleh hasil pengujian hipotesis secara parsial yakni sebagai berikut:

1. Variabel financial knowledge mempunyai $\mathrm{t}$ hitung sebesar $2.040>1.663$ dengan nilai signifikan sebesar 0,045 . Oleh karena itu nilai signifikan lebih kecil dari 0,05 atau nilai $0,045<0,05$ maka $\mathrm{H}_{\mathrm{a}}$ diterima dan $\mathrm{H}_{0}$ ditolak, artinya bahwa financial knowledge berpengaruh terhadap financial saticfaction pada dosen di Universitas Papua.
2. Variabel financial capability mempunyai $\mathrm{t}$ hitung sebesar $-0,088<1.663$ dengan nilai signifikan sebesar 0,930 . Oleh karena itu nilai signifikan lebih besar dari 0,05 atau nilai $0,930>0,05$ maka $\mathrm{H}_{0}$ diterima dan $\mathrm{H}_{\mathrm{a}}$ ditolak, artinya bahwa financial capability tidak berpengaruh terhadap financial saticfaction pada dosen di Universitas Papua.

3. Variabel financial behavior mempunyai $\mathrm{t}$ hitung sebesar $5.568>1.663$ dengan nilai signifikan sebesar 0,000 . Oleh karena itu nilai signifikan lebih kecil dari 0,05 atau nilai $0,000<0,05$ maka $\mathrm{H}_{\mathrm{a}}$ diterima dan $\mathrm{H}_{0}$ ditolak, artinya bahwa financial behavior berpengaruh terhadap financial saticfaction pada dosen di Universitas Papua.

Adapun untuk mengetahui semua variabel bebas yang dimasukkan dalam model mempunyai pengaruh secara bersama-sama terhadap variabel terikat digunakan uji F (Ghozali, 2006). Dasar pengambilan keputusannya adalah dengan menggunakan angka probabilitas signifikansi. Jika F hitung $\leq \mathrm{F}$ tabel, atau nilai signifikansi > 0,05 maka $\mathrm{H}_{0}$ diterima dan $\mathrm{H}_{\mathrm{a}}$ ditolak yang berarti tidak terdapat pengaruh yang signifikan antar variabel $X$ secara bersama-sama terhadap variabel terikat $\mathrm{Y}$ dan jika $\mathrm{F}$ hitung $>\mathrm{F}$ tabel, atau nilai signifikansi $\leq 0,05$ maka $\mathrm{H}_{0}$ ditolak dan $\mathrm{H}_{\mathrm{a}}$ diterima yang berarti terdapat pengaruh yang signifikan antar variabel $X$ secara bersamasama terhadap variabel terikat $\mathrm{Y}$.

Tabel 5 menyajikan hasil dari uji $F$ pada variabel bebas terhadapa variabel terikat dengan menggunakan taraf kepercayaan $95 \%$.

Tabel 5. Hasil Uji Simultan (Uji F) ANOVA $^{\text {a }}$

\begin{tabular}{lcrccc}
\hline Model & $\begin{array}{c}\text { Sum of } \\
\text { Squares }\end{array}$ & Df & $\begin{array}{c}\text { Mean } \\
\text { Square }\end{array}$ & F & Sig. \\
\hline Regression & 1180.337 & 3 & 393.446 & 11.403 & $0.000^{\mathrm{b}}$ \\
\hline Residual & 2794.887 & 81 & 34.505 & & \\
\hline Total & 3975.224 & 84 & & & \\
\hline
\end{tabular}

a. Dependent Variable: Financial Saticfaction

b. Predictors: (Constant), Financial Behavior, Financial Knowledge, Financial Capability

Sumber: Data primer yang diolah (2018)

Dari tabel 5 diperoleh nilai $\mathrm{F}$ hitung $>\mathrm{F}$ tabel yaitu $11.403>2,72$ dengan nilai signifikansi lebih dari nilai probabilitas 0,05 atau nilai 0,000 $<0,05$ berarti secara bersama-sama (simultan) variabel financial knowledge, financial capability, dan financial behavior berpengaruh signifikan terhadap financial saticfaction pada dosen di Universitas Papua. 


\section{KESIMPULAN}

Berdasarkan hasil analisa dari penelitian ini, maka dapat ditarik kesimpulan bahwa:

1. Financial knowledge berpengaruh secara parsial terhadap financial saticfaction pada dosen di Universitas Papua, dibuktikan dengan hasil uji hipotesis dimana tingkat signifikansi dibawah 0,05 yaitu 0,045 yang mengandung makna bahwa secara parsial financial knowledge berpengaruh terhadap financial saticfaction.

2. Financial capability berdasarkan hasil uji hipotesis menunjukkan tingkat signifikansi berada diatas 0,05 yaitu 0,930 . Hal tersebut menunjukkan bahwa financial capability secara parsial tidak berpengaruh terhadap financial saticfaction pada dosen di Universitas Papua

3. Financial behavior berpengaruh secara parsial terhadap financial saticfaction pada dosen di Universitas Papua. Hal tersebut dapat dilihat berdasarkn hasil pengolahan secara statistik menunjukkan nilai signifikan dibawah 0,05 yaitu 0,000 .

4. Financial knowledge, financial capability dan financial behavior berpengaruh secara simultan terhadap financial saticfaction pada dosen di Universitas Papua. Hal tersebut ditunjukkan dari nilai signifikansi berada dibawah 0,05 yaitu 0,000 .

5. Financial behavior merupakan faktor yang paling dominan berpengaruh terhadap financial saticfaction pada dosen di Universitas Papua. Hal tersebut dibuktikan dari hasil pengujian dimana nilai signifikansi sebesar 0,000 .

Sehingga secara keseluruhan pada penelitian ini dapat dijelaskan bahwa secara parsial financial knowledge, dan financial behavior berpengaruh sedangkan financial capability tidak berpengaruh terhadap financial saticfaction. Kemudian secara simultan semua faktor berpengaruh terhadap financial saticfaction dengan faktor financial behavior menjadi faktor yang paling dominan berpengaruh terhadap financial saticfaction.

\section{DAFTAR PUSTAKA}

Anonim. 2015. Orang Indonesia Makin Konsumtif. Http://Ekonomi.Kompas. Com/Read/2015/08/08/110746226/OJK.O rang.Indonesia.Makin.Konsumtif. Diakses pada 08 Desember 2017

Bank Indonesia. 2017. Jumlah Kredit Konsumtif Masyarakat Manokwari Selama Lima Priode Terakhir Kabupaten Manokwari. Manokwari: Bank Indonesia

Database UNIPA. 2018. Jumlah Dosen Aktif Mengajar di Universitas Papua. Manokwari:Bagian Kepegawaian UNIPA.

Ghozali, Imam. 2006. Aplikasi Analisis Multivariate Dengan Program SPSS. Semarang: Badan Penerbit UNDIP.

Joo dan Grable. 2004. An exploratory framework of the determinants of financial satisfaction. Journal of Family and Economic Issues, Vol 25.

Universitas Negeri Papua. 2009. Peraturan Akademik Universitas Negeri Papua Dan Petunjuk Pelaksanaan. Papua Barat: Universitas Negeri Papua.

Universitas Negeri Papua. 2017. Peraturan Akademik Universitas Negeri Papua Beserta Panjelasan. Papua Barat: Universitas Negeri Papua.

Vincentius, Andrew Dan Nanik, Linawati. 2014. Hubungan Faktor Demografi Dan Pengetahuan Keuangan Dan Perilaku Karyawan Swasta Di Surabaya. Jurnal Finesta Vol. 02, No. 02. 